\title{
Regulatory B Cells Limit CNS Inflammation and Neurologic Deficits in Murine Experimental Stroke
}

\author{
Xuefang Ren, ${ }^{1,4 \star}$ Kozaburo Akiyoshi, ${ }^{1 \star}$ Suzan Dziennis, ${ }^{1,4}$ Arthur A. Vandenbark, ${ }^{2,3,4,5}$ Paco S. Herson, ${ }^{1}$ \\ Patricia D. Hurn, ${ }^{1}$ and Halina Offner ${ }^{1,2,4}$ \\ Departments of ${ }^{1}$ Anesthesiology and Perioperative Medicine, ${ }^{2}$ Neurology, and ${ }^{3}$ Molecular Microbiology and Immunology, Oregon Health \& Science \\ University, Portland, Oregon 97239, and ${ }^{4}$ Neuroimmunology Research, R\&D31, and ${ }^{5}$ Research Service, Department of Veterans Affairs Medical Center, \\ Portland, Oregon 97239
}

Evaluation of infarct volumes and infiltrating immune cell populations in mice after middle cerebral artery occlusion (MCA0) strongly implicates a mixture of both pathogenic and regulatory immune cell subsets in stroke pathogenesis and recovery. Our goal was to evaluate the contribution of B cells to the development of MCAO by comparing infarct volumes and functional outcomes in wild-type (WT) versus B-cell-deficient $\mu \mathrm{MT}^{-1-}$ mice. The results clearly demonstrate larger infarct volumes, higher mortality, more severe functional deficits, and increased numbers of activated T cells, macrophages, microglial cells, and neutrophils in the affected brain hemisphere of MCAOtreated $\mu \mathrm{MT}^{-1-}$ versus WT mice. These MCA0-induced changes were completely prevented in B-cell-restored $\mu \mathrm{MT}^{-1-}$ mice after $^{-{ }^{-1}}$ transfer of highly purified WT GFP ${ }^{+} \mathrm{B}$ cells that were detected in the periphery, but not the CNS. In contrast, transfer of B cells from IL-10 ${ }^{-I-}$ mice had no effect on infarct volume when transferred into $\mu \mathrm{MT}^{-1-}$ mice. These findings strongly support a previously unrecognized activity of IL-10-secreting WT B cells to limit infarct volume, mortality rate, recruitment of inflammatory cells, and functional neurological deficits $48 \mathrm{~h}$ after MCA0. Our novel observations are the first to implicate IL-10-secreting B cells as a major regulatory cell type in stroke and suggest that enhancement of regulatory B cells might have application as a novel therapy for this devastating neurologic condition.

\section{Introduction}

Animal data clearly support a biphasic effect of stroke on the peripheral immune system. The initial phase is characterized by early signaling from the ischemic brain to spleen, resulting in a massive production of inflammatory factors, transmigration of splenocytes to the circulation and infiltration of stroke-damaged areas of the brain by inflammatory polymorphonuclear cells, macrophages, T cells and B cells (Offner et al., 2006a). This early activation phase is followed by compensatory systemic immunosuppression that is manifested within days of focal stroke by a profound (90\%) loss of immune T and B cells in the spleen and

\footnotetext{
Received March 31, 2011; revised April 20, 2011; accepted April 24, 2011

Author contributions: P.D.H. and H.O. designed research; K.A. and X.R. performed research; X.R., S.D., A.A.V., P.S.H., P.D.H., and H.O. analyzed data; X.R. and H.O. wrote the paper.

This work was supported by NIH Grants NR03521 and NS49210. This material is based upon work supported in part by the Department of Veterans Affairs, Veterans Health Administration, Office of Research and Development, Biomedical Laboratory Research and Development. The contents do not represent the views of the Department of Veterans Affairs or the United States Government. We thank Dr. Heng Hu, Dr. Sushmita Sinha, Dr. Sheetal Bodhankar, and Ms. Sandhya Subramanian for helpful discussions; Dr. Takeru Shimizu for performing part of animal surgeries; and Ms. Eva Niehaus for assistance in preparing the manuscript.

${ }^{*} X . R$. and K.A. contributed equally to this work.

The authors declare no competing financial interests.

Correspondence should be addressed to Dr. Halina Offner, Neuroimmunology Research, R\&D-31, Portland Veterans Affairs Medical Center, 3710 SW US Veterans Hospital Road, Portland, OR 97239. E-mail address: offnerva@ohsu.edu.

K. Akiyoshi's present address: Kyushu University Hospital, Department of Anesthesiology and Critical Care Medicine, 3-1-1 Maidashi, Higashi-ku, Fukuoka 812-8582, Japan.

P. D. Hurn's present address: The University of Texas System, Office of Health Affairs, Austin, TX 78701.

DOI:10.1523/JNEUROSCI.1623-11.2011

Copyright $\odot 2011$ the authors $\quad 0270-6474 / 11 / 318556-08 \$ 15.00 / 0$
}

thymus and reduced T-cell activation (Offner et al., 2006b, 2009). These changes were accompanied by an increase in splenocytes that were overtly apoptotic or committed to the apoptotic pathway (i.e., that were TUNEL positive, Annexin $\mathrm{V}^{+}$, or $\mathrm{PI}^{+}$).

To evaluate the contribution of lymphocytes to stroke severity, we performed middle cerebral artery occlusion (MCAO) in SCID mice that are genetically deficient in $\mathrm{T}$ and $\mathrm{B}$ lymphocytes (Hurn et al., 2007). Cortical and total infarction volumes were strikingly smaller in the SCID mice with MCAO compared with wild-type (WT) C57BL/6 control mice $(p<0.01)$. The smaller infarct size in SCID versus WT mice indicated that $\sim 40 \%$ of the stroke damage observed within the first $22 \mathrm{~h}$ of MCAO involves the inflammatory $\mathrm{T}$ and/or B cells that have migrated from the periphery into the evolving infarct. However, the initial inflammatory ischemic insult may also induce regulatory responses that limit CNS damage.

A promising regulatory candidate was the $\mathrm{CD} 4{ }^{+} \mathrm{CD} 25^{+}$ FoxP $^{+}$T-cell population (Tregs), which increased significantly $96 \mathrm{~h}$ after MCAO (Offner et al., 2006b). However, depletion of Tregs using Foxp $3^{\text {DTR }}$ mice (Kim et al., 2007) did not affect infarct volume or behavioral evaluations in mice (Ren et al., 2011). Our failure to implicate Tregs in limiting brain lesion volume after MCAO is of general importance to the field because of the increased interest in using CD $4{ }^{+} \mathrm{Foxp}^{+}{ }^{+}$Tregs as a possible therapeutic approach in stroke. Our results differed from a recent report (Liesz et al., 2009) in which depletion of the CD25 ${ }^{+}$population with anti-CD25 mAbs significantly increased brain infarct volume and worsened functional outcome. Although these 
A

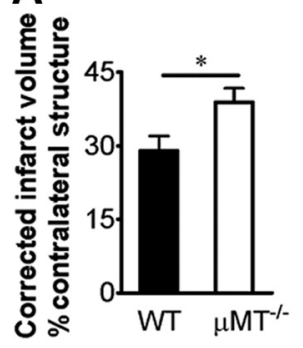

B

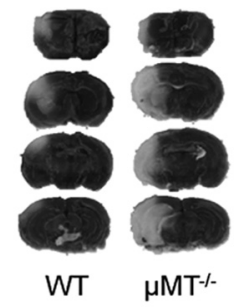

C

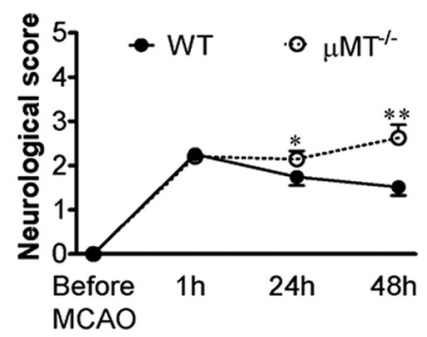

Figure 1. Deficiency of $B$ cells exacerbates ischemic infarct volume and behavioral outcome after MCA0. $A$, Infarct volume, corrected for the presence of edema, at $48 \mathrm{~h}$ of reperfusion after 60 min of MCAO given as bar graphs are visualized (mean \pm SEM). Statistical analysis was performed with the Student's $t$ test. There was a significant difference in infarct volumes between WT and $\mu \mathrm{MT}^{-1-}$ mice; ${ }^{*} p<0.05$. Groups: WT $(n=15) ; \mu \mathrm{MT}^{-1-}(n=12) . \boldsymbol{B}$, Representative TTC-stained cerebral sections of the MCA0 modeled to analyze infarct volume. Localization of the ischemic lesion differed between WT and $\mu \mathrm{MT}^{-/-}$mice. $C$, B-cell-deficient $\mu \mathrm{MT}^{-1-}$ mice had no significant functional worsening before reperfusion, but significantly worsened functional outcome at $24 \mathrm{~h}\left({ }^{*} p=0.02\right)$ and $48 \mathrm{~h}\left({ }^{* *} p=0.002\right)$ after reperfusion. The statistical analysis was performed using the MannWhitney $U$ test. Groups: WT $(n=35) ; \mu \mathrm{MT}^{-1-}(n=35)$.

\begin{tabular}{|c|c|c|c|c|c|c|}
\hline \multirow[b]{2}{*}{ Variables } & \multicolumn{3}{|l|}{ WT $(n=4)$} & \multicolumn{3}{|c|}{$\mu \mathrm{MT}^{-I-}(n=3)$} \\
\hline & Baseline & Mid-MCAO & End-MCAO & Baseline & Mid-MCAO & End-MCAO \\
\hline $\begin{array}{l}\text { Arterial } \\
\quad \text { blood pH }\end{array}$ & $7.38 \pm 0.06$ & $7.40 \pm 0.08$ & $7.4 \pm 0.06$ & $7.41 \pm 0.06$ & $7.43 \pm 0.05$ & $7.43 \pm 0.01$ \\
\hline $\begin{array}{l}\mathrm{PaCO} \\
\quad(\mathrm{mmHg})\end{array}$ & $32 \pm 4$ & $32 \pm 7$ & $34 \pm 8$ & $30 \pm 5$ & $29 \pm 5$ & $27 \pm 2$ \\
\hline $\begin{array}{l}\mathrm{PaO}_{2} \\
\quad(\mathrm{mmHg})\end{array}$ & $141 \pm 19$ & $137 \pm 19$ & $141 \pm 11$ & $145 \pm 7$ & $149 \pm 8$ & $144 \pm 8$ \\
\hline $\begin{array}{l}\text { MABP } \\
\quad(\mathrm{mmHg})\end{array}$ & $83 \pm 5$ & $83 \pm 5$ & $75 \pm 7$ & $87 \pm 3$ & $85 \pm 7$ & $70 \pm 11$ \\
\hline $\begin{array}{l}\text { Temperature } \\
\left({ }^{\circ} \mathrm{C}\right)\end{array}$ & $36.6 \pm 0.6$ & $36.6 \pm 0.4$ & $36.3 \pm 0.3$ & $36.4 \pm 0.3$ & $36.4 \pm 0.4$ & $36.3 \pm 0.6$ \\
\hline $\mathrm{rCBF}(\%)$ & $100 \pm 0$ & $13 \pm 7$ & $18 \pm 9$ & $100 \pm 0$ & $12 \pm 0$ & $7 \pm 2$ \\
\hline
\end{tabular}

There were no differences in physiological parameters determined between the genotypes. $\mathrm{PaCO}_{2}$, Arterial $\mathrm{CO}_{2}$ tension; $\mathrm{PaO}_{2}$, arterial $\mathrm{O}_{2}$ tension; $\mathrm{MABP}$, mean arterial blood pressure; $\mathrm{rCBF}$, regional cerebral blood flow.

effects cannot be attributed solely to $\mathrm{CD} 4{ }^{+} \mathrm{CD} 25^{+} \mathrm{Foxp} 3^{+}$Tregs due to a wider expression of CD25, this study did implicate activated $\mathrm{T}$ - and/or B-cell populations in a regulatory role.

Recent studies have described powerful regulatory effects of $\mathrm{B}$ lymphocytes on inflammatory responses (LeBien and Tedder, 2008; Lund, 2008). Depletion of B cells worsened disease severity in models of multiple sclerosis, and transfer of WT B cells provided protection against disease induction (Matsushita et al., 2010). The ability of the $\mathrm{CD} 1 \mathrm{~d}^{\text {high }} \mathrm{CD} 5^{+} \mathrm{CD} 19^{+}$regulatory B-cell subset to limit CNS injury is likely associated with the well recognized anti-inflammatory effects of IL-10 in the CNS (Fillatreau et al., 2002; Mann et al., 2007). We thus evaluated the effects of regulatory B cells in stroke. Our data demonstrate the profound impact of endogenous regulatory B cells on limiting the infarct volume and neurological deficits after ischemic stroke, and further identify the cellular targets of this highly protective B-cell population.

\section{Materials and Methods}

Animals. B-cell-deficient $\mu \mathrm{MT}^{-1-}$ mice on the C57BL/6 background were bred at the VA Animal Resource Facility. Age-matched 8-12-weekold C57BL/6 mice (WT, Jackson Laboratory) were used as control mice for MCAO induction. Green fluorescent protein $\left(\mathrm{GFP}^{+}\right)$mice (bred at the VA Animal Resource Facility), WT and IL- $10^{-1-}$ mice (the Jackson Laboratory) on the C57BL/6 background were used as B-cell donors to restore B-cell function in B-cell-deficient mice. Animals were bred and cared for according to institutional guidelines in the Animal Resource Facility at the Veterans Affairs Medical Center, Portland, OR. All experiments were performed under approved institutional protocols from the VA and Oregon Health \& Science University.

$M C A O$ model. The mice were subjected to MCAO as previously published (Offner et al., $2006 \mathrm{~b})$ by reversible right MCA occlusion $(60$ min) under isoflurane anesthesia, followed by $48 \mathrm{~h}$ of reperfusion. Body and head temperatures were controlled at $37 \pm 0.5^{\circ} \mathrm{C}$. Occlusion and reperfusion were verified in each animal by laser Doppler flowmetry (Moor Instruments).

Quantification of infarct. As previously published, brains were collected at $48 \mathrm{~h}$ for standard 2,3,5-triphenyltetrazolium chloride (TTC) histology and digital image analysis of infarct volume. To control for edema, corrected infarct volume is expressed as a percentage of the contralateral structure (i.e., cortex, striatum, or total hemisphere).

Neurological deficit score. Neurological function was evaluated using a 0 -5-point scale neurological score: $0=$ no neurological dysfunction; $1=$ failure to extend left forelimb fully when lifted by tail: 2 = circling to the contralateral side; $3=$ falling to the left; $4=$ no spontaneous walk or in a comatose state; $5=$ death. The scores were assessed in a blinded fashion.

Cell isolation. Peripheral blood mononuclear cells were prepared by using red cell lysis buffer (eBioscience) following manufacturer's instructions. Single-cell suspensions from lymph nodes (LNs) (superficial cervical, mandibular, axillary, lateral axillary, superficial inguinal, and mesenteric) and spleens were prepared by mechanical disruption. For preparation of inflammatory cells in brain infarction, each mouse was transcardially perfused with $30 \mathrm{ml}$ of saline to exclude blood cells. The forebrain was dissected from the cerebellum and suspended in RPMI1640 medium. The suspension was digested with type IV collagenase (1 $\mathrm{mg} / \mathrm{ml}$, Sigma-Aldrich) and DNase I (50 $\mu \mathrm{g} / \mathrm{ml}$, Roche Diagnostics) at $37^{\circ} \mathrm{C}$ for $45 \mathrm{~min}$ in a shaker at 180 times per minute. Inflammatory cells were isolated by $37-70 \%$ Percoll (GE Healthcare) density gradient centrifugation according to a method described previously (Campanella et al., 2002). Inflammatory cells were removed from the interface for further analysis. The cells were then washed twice with RPMI-1640 medium, counted, and resuspended in stimulation medium containing 10\% FBS for phenotyping.

Analysis of cell populations by FACS. Anti-mouse antibodies used for this study included: CD19 (1D3, BD PharMingen), CD45 (30-F11, Invitrogen), CD11b (M1/70, eBioscience), MHCII (2G9, BD PharMingen), Gr1 (IA8, BD Horizon), CD3 (17A2, eBioscience), IFN- $\gamma$ (XMG1.2, eBioscience), TNF- $\alpha$ (MP6-XT22, BD PharMingen), and IL-10 (JES5$16 \mathrm{E} 3$, eBioscience). Single-cell suspensions were washed with staining medium (PBS containing $0.1 \% \mathrm{NaN} 3$ and $2 \%$ FCS). After incubation with appropriate $\mathrm{mAbs}$ and washing, cells were acquired with LSRII Fluorescence Activated Cell Sorter (BD Biosciences). For each experiment, cells were stained with appropriate isotype control antibodies to establish background staining and to set quadrants before calculating the percentage of positive cells. Data were analyzed using FlowJo software (TreeStar).

$\mathrm{CD}_{19^{+}} \mathrm{B}$-cell sorting and transfer. B cells were isolated for transfer experiments by negative magnetic cell sorting (Miltenyi Biotec), with $\mathrm{GFP}^{+}, \mathrm{WT}$, and IL-10 ${ }^{-1-}$ mice as donors. $\mu \mathrm{MT}^{-1-}$ mice were injected intraperitoneally with a total of $5 \times 10^{7} \mathrm{CD} 19^{+} \mathrm{B}$ cells for all cell transfer experiments. The purity of $\mathrm{B}$ cells was $>99 \%$. The distribution of $\mathrm{GFP}^{+} \mathrm{CD} 19^{+} \mathrm{B}$ cells was evaluated $48 \mathrm{~h}$ after transfer in recipient $\mu \mathrm{MT}^{-1-}$ mice.

IL-10 staining. Intracellular IL-10 expression was visualized by modification of a previously published immunofluorescence staining protocol (Yanaba et al., 2008). Briefly, isolated leukocytes or purified cells were resuspended $\left(2 \times 10^{6}\right.$ cells $\left./ \mathrm{ml}\right)$ in complete medium [RPMI-1640 media containing $10 \%$ FCS, $1 \mathrm{~mm}$ pyruvate, $200 \mu \mathrm{g} / \mathrm{ml}$ penicillin, $200 \mathrm{U} / \mathrm{ml}$ 
streptomycin, $4 \mathrm{~mm} \mathrm{~L}$-glutamine, and $5 \times 10^{-5 \mathrm{M}} 2$ - $\beta$-ME with LPS (10 $\mu \mathrm{g} / \mathrm{ml})$, PMA (50 $\mathrm{ng} / \mathrm{ml})$, ionomycin $(500 \mathrm{ng} / \mathrm{ml})$, and brefeldin A (10 $\mu \mathrm{g} / \mathrm{ml}$ ) ] (all reagents are from Sigma-Aldrich) for $5 \mathrm{~h}$. For IL-10 detection, Fc receptors were blocked with mouse Fc receptor-specific $\mathrm{mAb}$ (2.3G2; BD PharMingen) before cell surface staining, and then fixed and permeabilized with the Fixation/Permeabilization buffer (eBioscience), according to the manufacturer's instructions. Permeabilized cells were washed with $1 \times$ Permeabilization Buffer (eBioscience) and stained with APC-conjugated anti-IL-10 mAb (JES5-16E3, eBioscience). Isotypematched $\mathrm{mAbs}$ served as negative controls to demonstrate specificity and to establish background IL-10 staining levels.

Immunohistochemistry. Brains, lymph nodes, and spleens were collected from perfused $\mu \mathrm{MT}^{-1-}$ mice that received adoptively transferred $\mathrm{GFP}^{+} \mathrm{B}$ cells after $60 \mathrm{~min}$ of MCAO and $48 \mathrm{~h}$ reperfusion. Tissues were fixed with $4 \%$ buffered formalin, paraffin embedded, and sectioned. Sections were incubated with anti-GFP (Cell Signaling Technology), followed by incubation with secondary biotinylated antibody (goat anti-rabbit, Cell Signaling Technology) and staining with Vectastain ABC Peroxidase Kit (Vector Laboratories) and 3', 3diaminobenzidine (Sigma-Aldrich). Nuclear staining was performed with hematoxylin (Sigma-Aldrich).

Statistical analysis. Data were reported as means \pm SEM. Statistical analyses were performed using the appropriate test indicated in the figure legends as follows: Student's $t$ test for infarct volume; Mann-Whitney $U$ test for neuroscores; and Fisher's exact test for comparison of mortality rates incurred from surgery and induction of MCAO. $p$ values $\leq 0.05$ were considered statistically significant.

\section{Results}

\section{B-cell deficiency exacerbates stroke outcomes and alters cerebral inflammatory cell invasion}

B-cell-deficient $\mu \mathrm{MT}^{-1-}$ mice sustained significantly larger total hemisphere infarcts $(p<0.05)$ relative to WT mice (Fig. $1 A)$. Representative histologic staining of injured brain is shown in Figure $1 B$. These data clearly implicate the role of B cells in limiting histological damage after MCAO. Mortality was also higher in B-celldeficient versus WT mice (11/35 vs $3 / 35$, respectively; $p=0.017)$. Neurological scores were similar among all animals as assessed during MCAO immediately before reperfusion (Fig. 1C) $(p=0.36)$. However, B-cell-deficient mice exhibited worse functional outcomes at both $24 \mathrm{~h}$ (Fig. $1 C)(p=0.02)$ and $48 \mathrm{~h}$ of reperfusion (Fig. 1C) $(p=0.002)$ compared with WT mice. To confirm that the ischemic insult was equivalent among all animals, relevant physiological parameters were assessed before and during MCAO. As is shown in Table 1, rectal temperature, mean arterial blood pressure, arterial blood gases, and $\mathrm{pH}$ were comparable between groups. Similarly, intraischemic cortical blood flow, as estimated by laser Doppler flowmetry, was not different between B-cell-deficient and WT mice.

Leukocytes are major effectors of inflammatory damage after experimental brain ischemia (Gee et al., 2007; Wang et al., 2007). To determine whether the lack of B cells altered leukocyte composition in brain after MCAO, numbers of infiltrating $\mathrm{Gr}^{+}$neutrophils, $\mathrm{CD} 3^{+} \mathrm{T}$ cells, $\mathrm{CD} 11 \mathrm{~b}{ }^{+} \mathrm{CD} 45^{\text {low }}$ microglia, and $\mathrm{CD} 11 \mathrm{~b}{ }^{+} \mathrm{CD} 45^{\text {high }}$ macrophages were evaluated by flow cytometry. After $48 \mathrm{~h}$ reperfusion, the accumula-

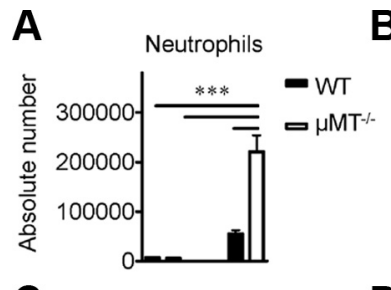

B
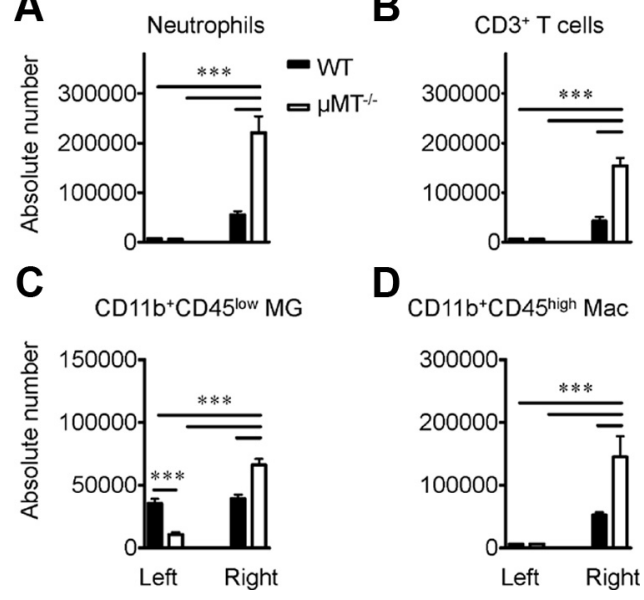

D

$\mathrm{CD} 11 \mathrm{~b}^{+} \mathrm{CD} 45^{\text {high }} \mathrm{Mac}$

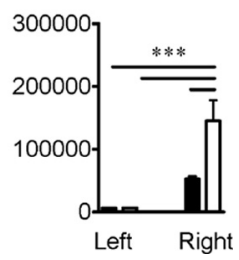

Figure 2. $A-D, B$ cells reduce the infiltration of inflammatory cells into the ischemic brain after MCA0. Analysis of $\mathrm{Gr}^{+}$neutrophils $(\boldsymbol{A}), \mathrm{CD}^{+}{ }^{+} \mathrm{T}$ cells $(\boldsymbol{B}), \mathrm{CD} 11 \mathrm{~b}{ }^{+} \mathrm{CD} 45^{\text {low }}$ microglia (MG) (C), and CD11b ${ }^{+}$CD45 high macrophages (Mac) (D) counted in the nonischemic (left) and ischemic (right) hemispheres. Values represent mean numbers ( \pm SEM) of indicated cell subsets from five mice in each group. Statistical analysis was performed with ANOVA followed by post hoc Tukey's test, respectively. Significant differences between sample means are indicated $\left({ }^{* * *} p<0.0001\right)$.
A

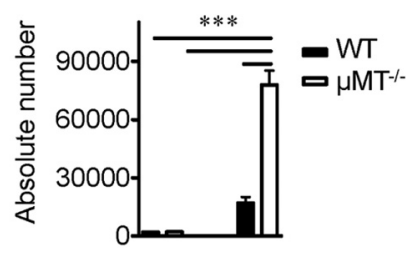

B

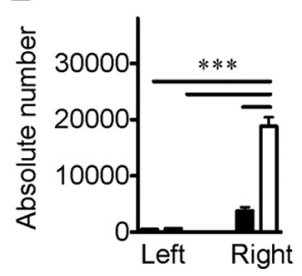

C

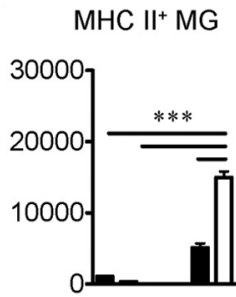

D $\quad \mathrm{TNF}-\mathrm{\alpha}^{+} \mathrm{MG}$

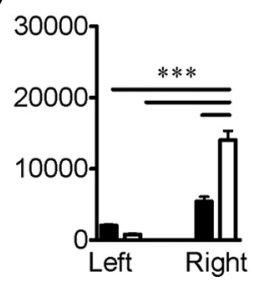

E

$\mathrm{MHC} \mathrm{II}^{+} \mathrm{Mac}$

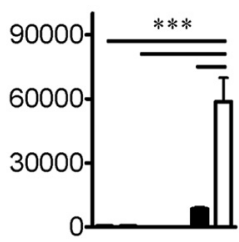

F $\quad \mathrm{TNF}^{-\alpha^{+} \mathrm{Mac}}$

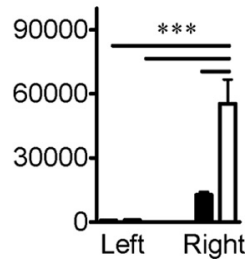

Figure 3. $\boldsymbol{A}-\boldsymbol{F}, \mathrm{B}$ cells reduce the activation of infiltrating inflammatory cells in the ischemic brain after MCAO. Deter作 WT and $\mu \mathrm{MT}^{-1-}$ mice after MCAO. Values represent mean numbers ( \pm SEM) of indicated cell subsets from five mice of each group. Statistical analysis was performed with ANOVA followed by post hoc Tukey's test, respectively. Significant differences between sample means are indicated $\left({ }^{* * *} p<0.0001\right)$.

tion of all of these leukocyte subtypes was significantly greater in the affected hemisphere of MCAO-treated $\mu \mathrm{MT}^{-1-}$ mice compared with MCAO-treated WT mice (Fig. $2 A-D$ ). Lack of B cells in $\mu \mathrm{MT}^{-/-}$mice further permitted significant increases in the absolute number of IFN- $\gamma$ - and TNF- $\alpha$-secreting CD3 $+\mathrm{T}$ cells and MHC class II + and TNF- $\alpha$-secreting microglia and macrophages in the ipsilateral hemisphere of MCAO mice at $48 \mathrm{~h}$ of reperfusion (Fig. $3 A-F$ ). In addition to the cell types mentioned above, we detected $6576 \pm 829 \mathrm{CD} 9^{+} \mathrm{B}$ cells per hemisphere in sham-treated brains $(n=5)$, not different from $7092 \pm$ 637 "resident" B cells in naive brains $(n=5)$. In MCAO mice, there were modest but significant increases to $9766 \pm 1832 \mathrm{~B}$ cells in the nonischemic hemisphere and 12,282 $\pm 824 \mathrm{~B}$ cells in the ischemic hemisphere $(n=5)$. 
A Splenocytes

B cells

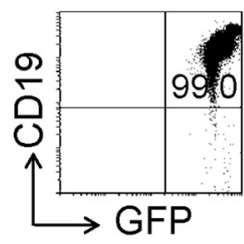

$\mu \mathrm{MT}^{-/-}$mice

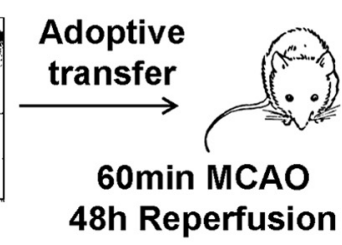

B
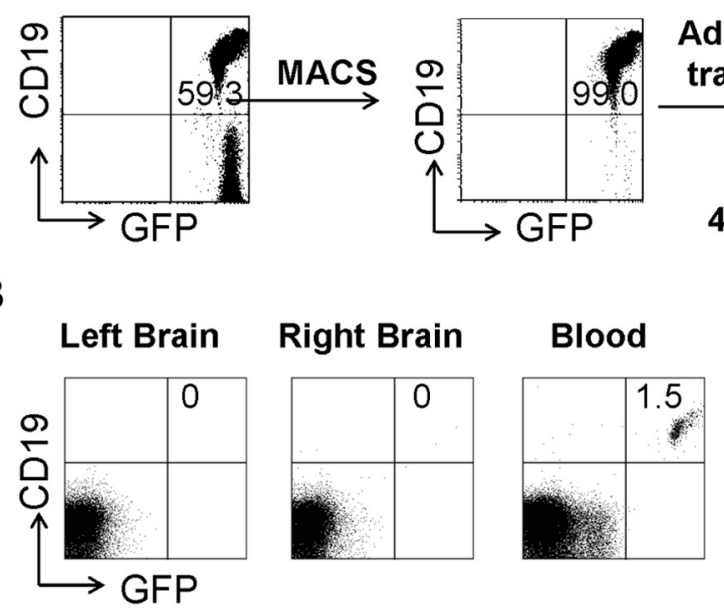

LN

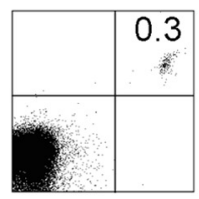

SP Peritoneal Cavity
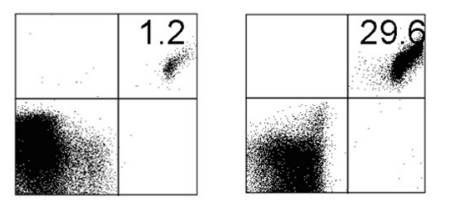

C
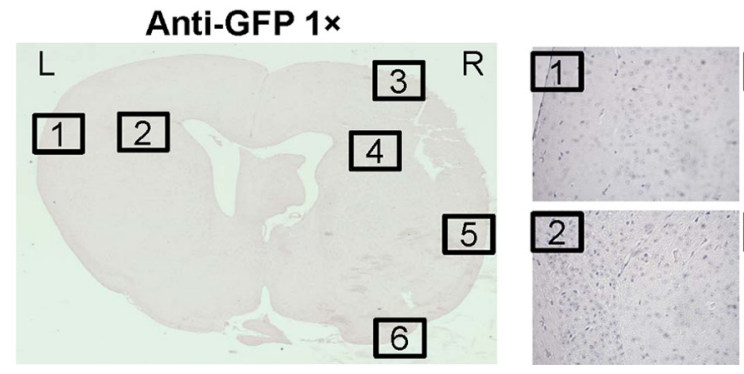

Anti-GFP 40x
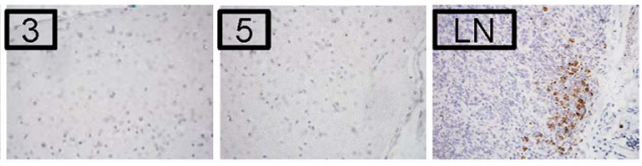

4
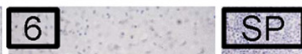

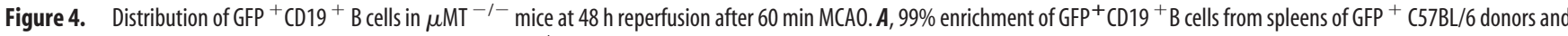
adoptive intraperitoneal transfer of 50 million B cells into $\mu \mathrm{MT}^{-/-}$mice. $\boldsymbol{B}$, Transferred GFP ${ }^{+} \mathrm{CD}_{19}{ }^{+} \mathrm{B}$ cells were not detected in either the nonischemic (left brain) or ischemic (right brain) hemispheres, but were observed in blood, LNs, spleen (SP), and peritoneal cavity of recipient mice by FACS at $48 \mathrm{~h}$ reperfusion after 60 min MCA0. C, Transferred GFP ${ }^{+}$B cells were visualized in LNs and spleens but not in the brains by immunohistochemical staining at $48 \mathrm{~h}$ reperfusion after $60 \mathrm{~min}$ MCAO.

\begin{abstract}
Adoptive transfer of $\mathrm{B}$ cells to $\mu \mathrm{MT}^{-/-}$mice reduces
\end{abstract} ischemic infarct size and improves neurological deficits To specifically implicate B cells as the protective cell type, highly enriched populations of B cells were transferred from WT donors to B-cell-deficient recipient mice before MCAO. As illustrated in Figure $4 A, \mathrm{CD} 9^{+} \mathrm{B}$ cells were obtained and enriched to $99 \%$ purity by negative selection from splenocytes of transgenic $\mathrm{GFP}^{+}$mice, and 50 million $\mathrm{GFP}^{+} \mathrm{CD}_{19}{ }^{+} \mathrm{B}$ cells were injected intraperitoneally into $\mu \mathrm{MT}^{-1-}$ mice $1 \mathrm{~d}$ before MCAO. The B-cell-deficient animals that received adoptively transferred $\mathrm{GFP}^{+} \mathrm{CD} 19^{+} \mathrm{B}$ cells had reduced infarct volumes $(p>0.05)$ after MCAO compared with no-celltransfer (PBS) controls (Fig. 5A,B), as well as a lower mortality rate $(p=0.05)$. Consistent with smaller infarction size, neurological outcome scores were also improved in B-cell-restored $\mu \mathrm{MT}^{-1-}$ mice with stroke after $48 \mathrm{~h}$ reperfusion compared with no-cell-transfer (PBS) control mice (Fig. 5C). We also confirmed that the adoptive transfer of $\mathrm{CD} 19^{+} \mathrm{B}$ cells from C57BL/6 WT donors $\left(\mathrm{GFP}^{-}\right)$limited stroke infarct size and functional outcome (data not shown). These findings clearly demonstrate that WT CD19 ${ }^{+} \mathrm{B}$ cells can restore improved ischemic outcomes in B-cell-deficient $\mu \mathrm{MT}^{-1-}$ mice. However, after $48 \mathrm{~h}$ of reperfusion transferred $\mathrm{GFP}^{+} \mathrm{B}$ cells could be detected in blood, LNs, spleen, and peritoneal cavity, but not in ischemic (Fig. $4 B$, left brain) or nonischemic (Fig. $4 B$, right brain) of recipient $\mu \mathrm{MT}^{-1-}$ mice by FACS. Immunohistochemical staining showed $\mathrm{GFP}^{+}$cells distributed in lymph nodes and spleens, but not in nonischemic (Fig. 4C, L) or ischemic (Fig. $4 C, \mathrm{R})$ hemispheres.
$B$ cells, but not $\mathrm{T}$ cells, are the major producer of IL-10 in MCAO mice

Because of the significant B-cell-dependent activity in limiting stroke infarct size and functional outcome demonstrated above, we hypothesized that the protective actions of $\mathrm{CD} 9^{+} \mathrm{B}$ cells might be linked to IL-10 production, a major regulatory cytokine known to be produced by both B cells and T cells. Thus, intracellular staining of IL-10 was performed in $\mathrm{CD} 19^{+} \mathrm{B}$ cells and $\mathrm{CD}^{+}{ }^{+} \mathrm{T}$ cells harvested from immune organs after MCAO and stimulated ex vivo with LPS, PMA, and ionomycin. As is shown in Figure 6, an increased percentage of IL-10-secreting CD3negative cells was observed in MCAO WT mice but not in $\mu \mathrm{MT}^{-1-}$ mice after $48 \mathrm{~h}$ reperfusion in blood, but not in spleen or lymph nodes. These IL-10-secreting cells in blood were identified as $\mathrm{CD} 19^{+}$B lymphocytes (Fig. 7). These data demonstrate enhanced availability of B cells with potential to limit ischemic and neurological outcomes after MCAO through secretion of IL-10.

\section{Adoptive transfer of IL-10 ${ }^{-/-} \mathrm{B}$ cells to $\mu \mathrm{MT}^{-/-}$mice does not reduce ischemic infarct size or improve neurological deficits}

To specifically address the mechanism of $B$ cells as the protective cell type producing IL-10, highly enriched populations of B cells were transferred from IL-10 $10^{-1-}$ donors to B-cell-deficient recipient mice before MCAO. As shown in Figure $8, A$ and $B$, the $B$-cell-deficient animals that received adoptively transferred IL$10^{-1-} \mathrm{B}$ cells did not exhibit significantly reduced infarct vol- 


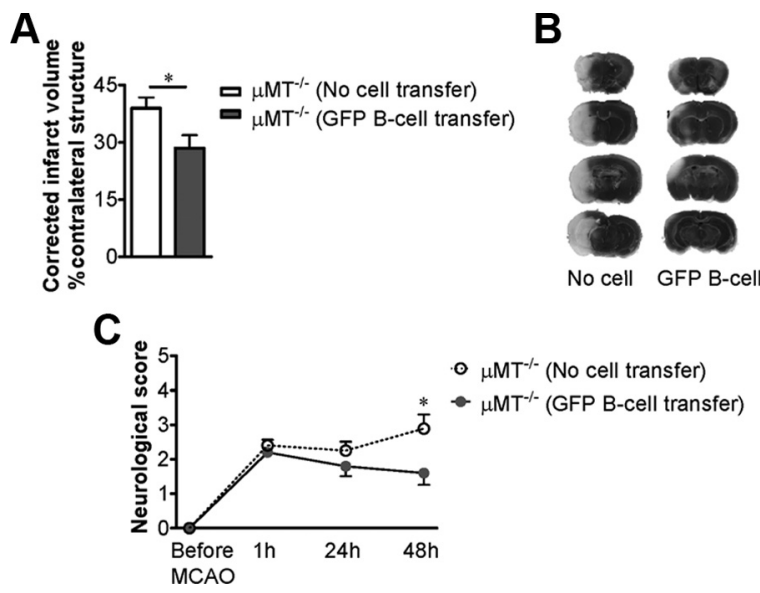

Figure 5. Transfer of GFP ${ }^{+} \mathrm{CD} 19^{+} \mathrm{B}$ cells reduces infarct volume and improves behavioral outcome of $\mu \mathrm{MT}^{-1-}$ B-cell-deficient mice. $A$, Transfer of 50 million $\mathrm{GFP}^{+} \mathrm{CD}_{19}{ }^{+} \mathrm{B}$ cells resulted in reduced infarct volume (mean $\pm S E M$ ) at $48 \mathrm{~h}$ of reperfusion after 60 of min MCA0. Statistical analysis was performed using the Student's $t$ test. There was a significant difference of infarct volumes between no cell (PBS) $(n=12)$ and GFP ${ }^{+}$B cell $(n=10)$ transferred $\mu \mathrm{MT}^{-1-}$ mice $\left(^{*} p>0.05\right) . B$, Representative TTC-stained cerebral sections of the MCAO modeled to analyze infarct volume. Localization of the ischemic lesion differed between no cell and B-cell-transferred $\mu \mathrm{MT}^{-1-}$ mice. C, Transfer of GFP ${ }^{+} \mathrm{B}$ cells did not change behavioral outcome in B-cell-deficient mice before reperfusion or after $24 \mathrm{~h}$ of reperfusion, but significantly improved functional outcome after $48 \mathrm{~h}$ of reperfusion compared with controls ( $\left.{ }^{*} p=0.04\right)$. The statistical analysis was performed using the Mann-Whitney $U$ test.

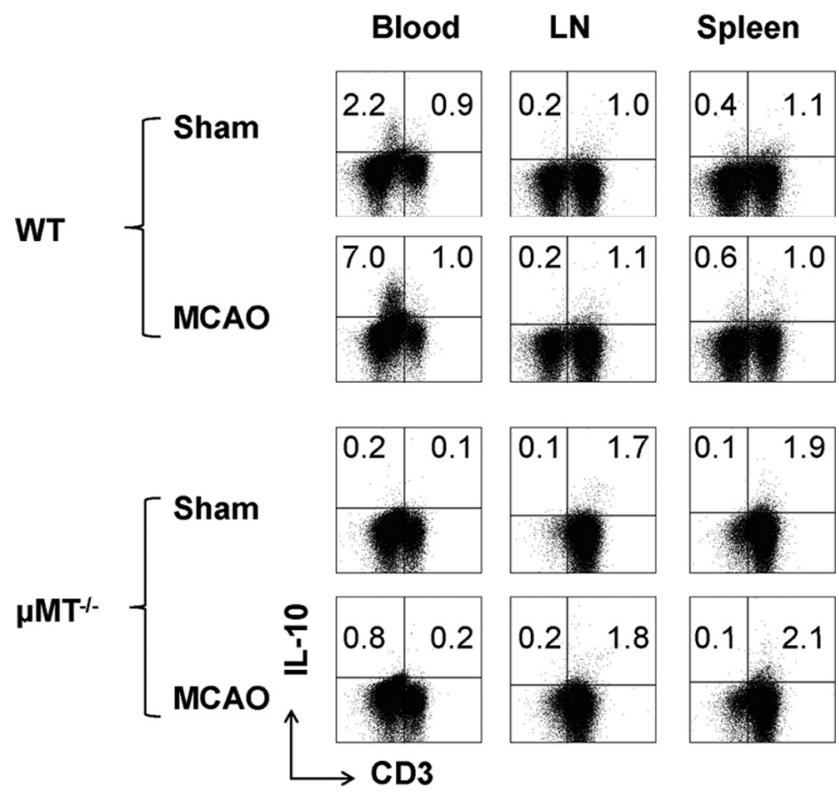

Figure 6. IL-10-secreting non-T cells, but not $T$ cells are increased after activation ex vivo in WT but not B-cell-deficient mice with MCAO. $\mathrm{CD}^{+}{ }^{+} \mathrm{T}$ cells and $\mathrm{CD} 3^{-}$non-T cells from blood, lymph nodes, and spleen were evaluated for intracellular expression of IL-10 after activation with LPS/PMA/ionomycin after $60 \mathrm{~min}$ of sham or MCA0 treatment and $48 \mathrm{~h}$ of reperfusion in WT and $\mu \mathrm{MT}^{-1-}$ mice. IL-10-secreting cells increased in blood are from $\mathrm{CD}^{-}$non-T cells after MCAO, and no increase in $\mathrm{LL}-10^{+} \mathrm{CD}{ }^{+} \mathrm{T}$ cells was found at this time point in blood, $\mathrm{LNs}$, or spleen tissue from MCAO mice. The leukocyte population was defined via forward scatter and sideward scatter parameters. Representative plots for one mouse show frequencies of IL-10producing cells among total lymphocytes within the indicated gates. Results represent one of five independent experiments producing similar results.

umes after $60 \mathrm{~min}$ MCAO followed by $48 \mathrm{~h}$ reperfusion compared with no-cell-transfer (PBS) controls. The mortality rate of the PBS and IL- $10^{-1-}$ B-cell transfer groups was 7 of 16 and 6 of 14, respectively. Moreover, there were no differences of

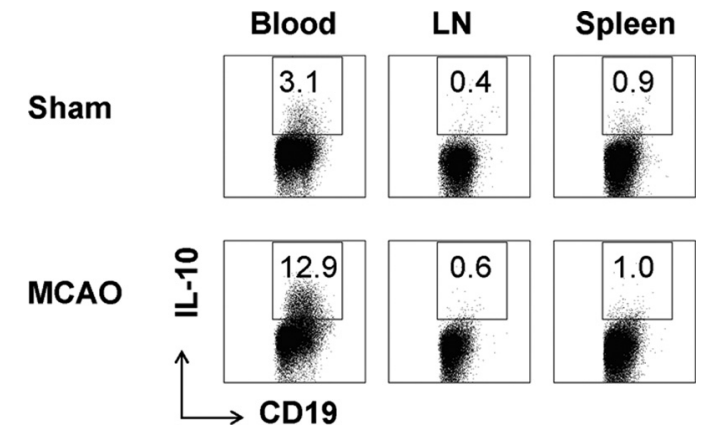

Figure 7. IL-10-secreting $B$ cells are increased after activation ex vivo in the blood of WT mice with MCA0. CD19 ${ }^{+} B$ cells from blood, lymph nodes, and spleen were evaluated for intracellular expression of IL-10 after activation with LPS/PMA/ionomycin after 60 min sham or MCA0 treatment and $48 \mathrm{~h}$ reperfusion in WT mice. CD19 staining was used as the initial gate for identifying $B$ cells. Representative plots for one mouse show increased frequencies of IL-10producing cells among total $B$ cells in blood within the indicated gates. Results represent one of three independent experiments producing similar results.
A
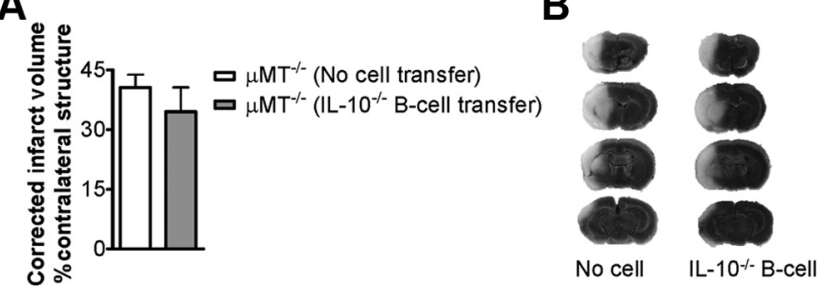

C

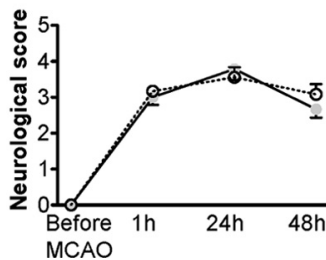

- $\mu \mathrm{MT}^{-/-}$(No cell transfer) $\therefore \mu \mathrm{MT}^{-/-}\left(\mathrm{IL}-10^{-/-} \mathrm{B}-\right.$ cell transfer $)$

Figure 8. Transfer of $\mathrm{IL}-10^{-1-} \mathrm{CD} 19^{+} \mathrm{B}$ cells does not alter infarct volume or improve behavioral outcome of $\mu \mathrm{MT}^{-/-}$mice. $A$, Transfer of 50 million $\mathrm{CD}_{19}{ }^{+} \mathrm{B}$ cells from IL-10 ${ }^{-/-}$ mice had no effect on infarct volume of total hemisphere (mean \pm SEM) at $48 \mathrm{~h}$ of reperfusion after 60 min of MCA0. Statistical analysis was performed using the Student's t test. There was no significant difference in infarct volumes between no-cell-transfer (PBS) $(n=9)$ and IL-10 ${ }^{-1-}$ B-cell-transferred $(n=8) \mu \mathrm{MT}^{-1-}$ mice. $\boldsymbol{B}$, Representative TTC-stained cerebral sections of the MCAO modeled to analyze infarct volume. Localization of the ischemic lesion did not differ between no-cell-transfer and IL-10 ${ }^{-1-}$ B-cell-transferred $\mu \mathrm{MT}^{-/-}$mice. C, Transfer of IL$10^{-I-}$ B cells did not significantly improve functional outcome after 24 or $48 \mathrm{~h}$ of reperfusion. The statistical analysis was performed using the Mann-Whitney $U$ test.

neurological outcome scores after 24 and $48 \mathrm{~h}$ of reperfusion between PBS and IL-10 ${ }^{-1-}$ B-cell transfer groups. Together, these data clearly demonstrate that WT CD $19^{+} \mathrm{B}$ cells can restore improved ischemic outcomes that were shown to be lacking in B-cell-deficient $\mu \mathrm{MT}^{-1-}$ mice through the secretion of IL-10.

\section{Regulatory B cells inhibit inflammatory responses in the} periphery of MCAO mice

To further evaluate possible regulatory effects of B cells on T-cell cytokine production during MCAO, inflammatory factors were quantified in blood and spleens after 60 min of MCAO and $48 \mathrm{~h}$ of reperfusion in WT mice, WT B-cell-restored $\mu \mathrm{MT}^{-1-}$ mice, and IL- $10^{-1-}$ B-cell-restored $\mu \mathrm{MT}^{-1-}$ mice. As is shown in Figure 9 , the percentages of both IFN- $\gamma$ - and TNF- $\alpha$-secreting $\mathrm{CD}^{+} \mathrm{T}$ cells were significantly increased in blood and spleen from B-cell-deficient versus WT mice, with a reduction to WT levels of these peripheral $\mathrm{T}$ cells in $\mu \mathrm{MT}^{-1-}$ mice after resto- 


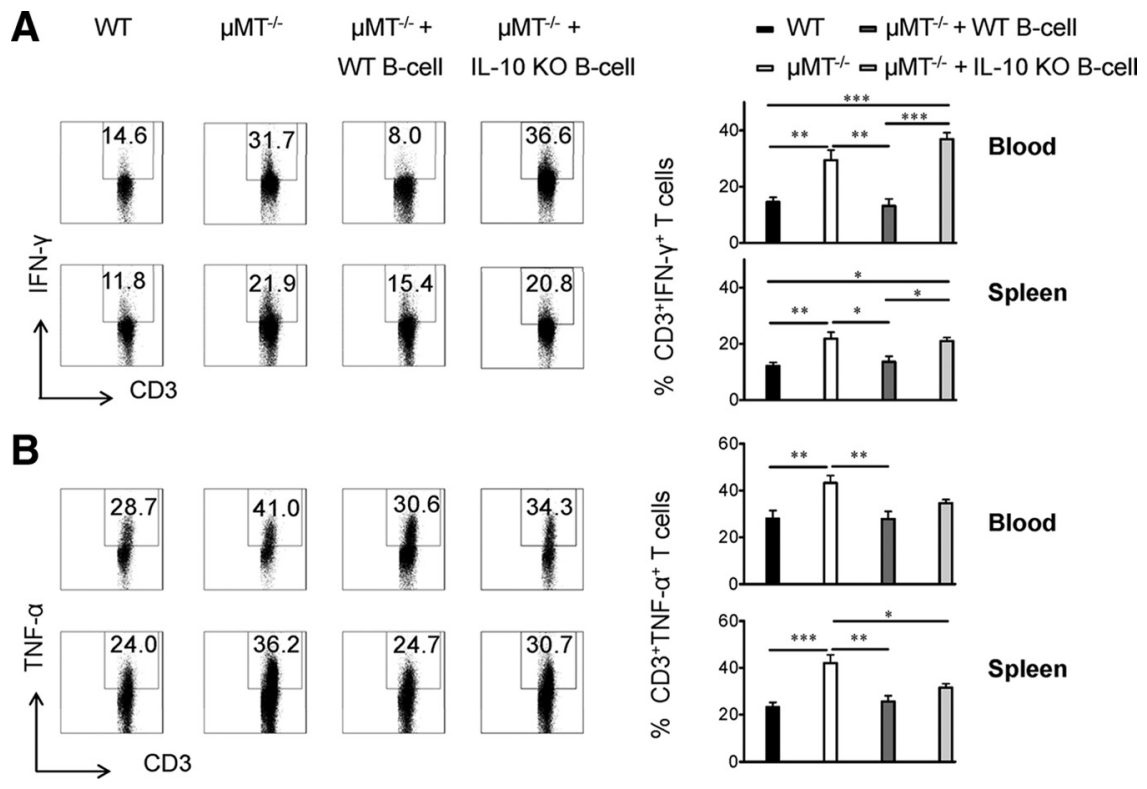

Figure 9. Increased cytokine production by T cells after MCAO in peripheral blood and spleen of B-cell-deficient $\mu M T^{-1-}$ mice is normalized after $B$-cell restoration. $\boldsymbol{A}, \boldsymbol{B}, \mathrm{CD}^{+}{ }^{+} \mathrm{T}$ cells from blood and spleen were evaluated for intracellular expression of IFN- $\gamma$ $(\boldsymbol{A})$ and TNF- $\alpha(\boldsymbol{B})$ after $60 \mathrm{~min}$ of MCAO and $48 \mathrm{~h}$ of reperfusion. CD3 staining was used as the initial gate for identifying T cells. Representative plots for one mouse show frequencies of IFN- $\gamma$ - or TNF- $\alpha$-producing T cells among total T cells within the indicated gates. Bar graphs indicate mean \pm SEM percentages of T cells that produced IFN- $\gamma$ or TNF- $\alpha$ in one representative experiment with five mice per group. Statistical analysis was performed using ANOVA followed by post hoc Tukey's test, respectively. Significant differences between sample means are indicated $\left({ }^{*} p<0.05 ;{ }^{* *} p<0.01\right)$.

ration with WT B cells, but not with IL-10 $0^{-1-}$ B cells. Thus, WT B cells with the potential for IL-10 secretion limited both inflammatory cytokine production of peripheral $\mathrm{T}$ cells (Fig. 9) and infiltration of inflammatory T cells (Fig. $3 A, B$ ) into the MCAO-affected hemisphere during MCAO.

\section{Discussion}

Much has been learned about factors that worsen or modulate stroke severity in animal models such as MCAO. Of importance are the effects on and contribution of the immune system in MCAO. The occlusion triggers early signaling from the ischemic brain to spleen, resulting in a massive production of inflammatory factors and transmigration of splenocytes to the circulation and brain. Whereas inflammatory cells from the periphery have now been shown to contribute to CNS damage and cell death, other regulatory immune cells can reduce inflammation and limit damage within the brain. A major conundrum in the immunology of stroke is how to enhance the early immunoregulation that limits CNS inflammation while preventing excessive systemic suppression. To do this in a strategic manner requires a full understanding of the involved inflammatory and regulatory immune pathways. To this end, we evaluated regulatory B cells from the peripheral immune system that can diminish stroke lesion size and protect from neurological damage.

The results presented above demonstrate the previously unrecognized activity of WT B cells to limit infarct volume and functional neurological deficits as well as to inhibit activation and recruitment of inflammatory $\mathrm{T}$ cells, macrophages, and microglia into the growing CNS infarct after experimental stroke in mice. These regulatory activities were not only significantly decreased in MCAO-treated B-cell-deficient $\mu \mathrm{MT}^{-1-}$ mice, but also were fully restored after passive transfer of WT B cells, thus implicating unequivocally the protective activity of regulatory B cells. These regulatory functions were associated with increased percentages of $\mathrm{IL}-10$-secreting $\mathrm{CD} 19^{+} \mathrm{B}$ cells in blood, but not IL-10-secreting T cells, including Tregs that have received much previous attention as possible immune regulators in stroke (Liesz et al., 2009). Our novel observations are the first to implicate $\mathrm{B}$ cells as a major regulatory cell type in stroke.

We demonstrated previously that the loss of B and T cells in SCID mice resulted in smaller infarct volumes (Hurn et al., 2007). Consistent with this concept, lymphocyte-deficient $\mathrm{RAG}^{-1-}$ mice sustained smaller infarct volumes and improved neurological deficit after MCAO (Yilmaz et al., 2006), and splenectomized rats given permanent MCAO exhibited reduced neurodegeneration and numbers of activated microglia, macrophages, and neutrophils in brain tissue (Ajmo et al., 2008). In the study by Yilmaz et al. (2006), $\mathrm{CD}^{+}$and $\mathrm{CD}^{+} \mathrm{T}$ cells contributed largely to postischemic intravascular inflammatory and prothrombotic responses in cerebral venules, and thus apparently could not account for the observed reduction in infarct volumes at $24 \mathrm{~h}$ postinjury. However, unlike our current results, their study did not detect improvement in MCAO outcomes in B-cell-deficient mice, perhaps due to differences in the animal model or experimental paradigm (Yilmaz et al., 2006). Another recent study (Kleinschnitz et al., 2010) failed to observe a protective effect of adoptively transferred B cells in RAG-1 ${ }^{-1-}$ mice treated with MCAO, a result possibly explained by the use of only 10 million transferred B cells (compared with 50 million cells used in our study) as well as the genetically induced lack of potentially neurotoxic $T$ cells that would need to be present to observe protective B-cell effects. It is noteworthy that we observed significant changes in neurological scores after MCAO, further strengthening our observations of worsened tissue injury size in B-celldeficient mice (Fig. 1). Both the previous studies and our present data were obtained in animals at fairly early recovery time points, when full maturation of the infarct has not yet occurred. This early window of observation is a limitation for all of these studies. We chose a $48 \mathrm{~h}$ recovery time to accommodate a potentially high mortality rate in the B-cell-deficient $\mu \mathrm{MT}^{-1-}$ mice treated with a standard MCAO and to minimize survivorship effects that are present in an animal that lacks all B-cell functions.

As for regulatory $\mathrm{T}$ cells, there remains substantial discord. The recent report by Liesz et al. (2009) found that depletion of the $\mathrm{CD} 25^{+}$population with anti-CD25 mAbs significantly increased brain infarct volume and worsened functional outcome. These effects were attributed to $\mathrm{CD} 4{ }^{+} \mathrm{CD} 25^{+}$Foxp $3{ }^{+}$Tregs, even though the anti-CD25 mAbs only depleted $\sim 50 \%$ of this Treg phenotype. On the other hand, our recent study using conditional Tregdeficient mice failed to implicate $\mathrm{CD} 4{ }^{+} \mathrm{CD} 25^{+} \mathrm{FoxP} 3{ }^{+}$Tregs as having protective activity against MCAO (Ren et al., 2011). It should be noted that CD25, the IL- 2 receptor chain- $\alpha$, has a broad expression on early progenitors of the T- and B-cell lineages, as well as on activated mature $\mathrm{T}$ and $\mathrm{B}$ cells. Thus, although our study did not demonstrate larger infarct volumes in Tregdeficient mice, it did not exclude the contribution of other regu- 
latory cells. From this perspective, the data from these previous reports do not preclude our current identification of regulatory $\mathrm{B}$ cells in MCAO.

A key function of B cells is their secretion of IL-10 (Carter et al., 2011), an anti-inflammatory cytokine that has been studied extensively in stroke (Planas et al., 2006). IL-10-deficient mice develop larger infarcts after permanent focal ischemia (Grilli et al., 2000), whereas administration of IL-10 to the lateral ventricle (Spera et al., 1998 ) or intraperitoneally in combination with hypothermia (Dietrich et al., 1999), by adenoviral vectors (Ooboshi et al., 2005), after induction of mucosal tolerance by IL-10-producing MOG (myelin oligodendrocyte glycoprotein)-reactive $\mathrm{T}$ cells (Frenkel et al., 2005), or by transgenic overexpression of IL-10 (de Bilbao et al., 2009), all reduced infarct volume. Moreover, IL-10 was found to prevent neuronal damage induced by excitotoxicity in vitro (Grilli et al., 2000). In the clinic, early worsening of stroke was associated with lower IL-10 plasma levels in patients with subcortical infarcts or lacunar stroke, but not in patients with cortical lesions (Vila et al., 2003). Conversely, excessive levels of IL-10 may predispose to increased infections (Chamorro et al., 2006). Together, these findings suggest that local secretion of IL-10 may be preferable to systemic delivery. Our study demonstrated that B cells are the major producer of IL-10 in WT mice and are enriched in the blood after MCAO (Figs. 6, 7), thus providing locally secreted IL-10 that would be missing in B-cell-deficient mice.

Expression of CD19 is almost completely restricted to B cells but may also be expressed in follicular dendritic cells, with some phenotypes shared with plasmacytoid dendritic cells (Bao et al., 2011). A minor population of splenic dendritic cells expresses CD19 and has been shown to mediate aspects of T-cell suppression through IFN signaling (Mellor et al., 2005). In our study, we used a negative B-cell-sorting strategy, which depleted mature $\mathrm{T}$ cells, NK cells, and myeloid lineage cells by anti-CD43 antibody. Thus, the significant protective effect in stroke provided by highly purified B cells would not likely be affected by the few remaining dendritic cells or other cell types. Although we cannot rule out that other protective mediators from regulatory B cells (Bregs), such as transforming growth factor (TGF- $\beta$ ) (Tian et al., 2001) or direct cellular interactions, could contribute to B-cell-mediated protection, we concentrated on IL-10 as a universal protective mechanism used by Bregs. IL-10 potently reduced infarct size in normal mice in a previous study, and our present report strongly supports the contention that B cells do not protect against ischemic injury (Fig. 8) or peripheral inflammation (Fig. 9) in the absence of IL-10.

In the adoptive transfer assay, we detected a small percentage of engrafted $B$ cells in peripheral blood and immune organs after stroke (Fig. $4 B, C$ ), even though some $\mathrm{B}$ cells were retained in the peritoneal cavity $3 \mathrm{~d}$ after adoptive transfer (Fig. $4 B$ ). Higher engraftment has been reported previously in $\mu \mathrm{MT}^{-1-}$ using $1.5 \times 10^{7}$ transferred B cells (Roth and Mamula, 1997), compared with the $5 \times 10^{7} \mathrm{CD} 19^{+} \mathrm{B}$ cells used in the current study. Some of the transferred B cells in our study likely did not survive due to ischemia-induced B-cell depletion (Offner et al., 2006), although it has been reported that resting B cells may survive for at least 2 months after transfer into recipient mice (Gray, 1988). In the current study, transferred $\mathrm{GFP}^{+} \mathrm{B}$ cells could not be detected in the brain (Fig. 4), which suggested that the regulatory effects of Bregs in this model could occur entirely in the periphery (Fig. 9). However, the stronger inflammatory response in CNS (Figs. 2, 3) of $\mu \mathrm{MT}^{-1-}$ mice could be from infiltrating inflammatory cells from the periphery. Moreover, CNS microglia might be directly or indirectly activated (Fig. 3) by inflammatory components.

Recent studies have identified a subpopulation of CD1d ${ }^{\text {high }}$ $\mathrm{CD} 5{ }^{+} \mathrm{CD} 19^{+}$"regulatory B cells," and we also investigated changes in these CD1 ${ }^{\text {high }} \mathrm{CD} 5{ }^{+}$Bregs in stroke. To our surprise, the IL-10-secreting population was not restricted to either the CD1d ${ }^{\text {high }}$ or the $\mathrm{CD} 5^{+}$population poststroke (data not shown). We thus conclude that IL-10 is more specific than the CD1d ${ }^{\text {high }} \mathrm{CD}^{+} 19^{+}$B-cell subset markers for identification of Bregs in stroke. In conclusion, our study provides new insights into the endogenous inflammatory response after acute brain ischemia. Specifically, we have described a previously unknown role for $\mathrm{B}$ cells as cerebroprotective immunomodulators after stroke, a function that affects diverse cytokine-dependent and cellular inflammatory targets through the anti-inflammatory effects of IL-10.

\section{References}

Ajmo CT Jr, Vernon DO, Collier L, Hall AA, Garbuzova-Davis S, Willing A, Pennypacker KR (2008) The spleen contributes to stroke-induced neurodegeneration. J Neurosci Res 86:2227-2234.

Bao Y, Han Y, Chen Z, Xu S, Cao X (2011) IDN- $\alpha$-producing PDCA-1+ Siglec-H- B cells mediate innate immune defense by activating NK cells. Eur J Immunol 41:657-668.

Campanella M, Sciorati C, Tarozzo G, Beltramo M (2002) Flow cytometric analysis of inflammatory cells in ischemic rat brain. Stroke 33:586-592.

Carter NA, Vasconcellos R, Rosser EC, Tulone C, Muñoz-Suano A, Kamanaka M, Ehrenstein MR, Flavell RA, Mauri C (2011) Mice lacking endogenous IL-10-producing regulatory $\mathrm{B}$ cells develop exacerbated disease and present with an increased frequency of Th1/Th17 but a decrease in regulatory T cells. J Immunol 186:5569-5579.

Chamorro A, Amaro S, Vargas M, Obach V, Cervera A, Torres F, Planas AM (2006) Interleukin 10, monocytes and increased risk of early infection in ischemic stroke. J Neurol Neurosurg Psychiatry 77:1279-1281.

de Bilbao F, Arsenijevic D, Moll T, Garcia-Gabay I, Vallet P, Langhans W, Giannakopoulos P (2009) In vivo over-expression of interleukin-10 increases resistance to focal brain ischemia in mice. J Neurochem 110:12-22.

Dietrich WD, Busto R, Bethea JR (1999) Postischemic hypothermia and IL-10 treatment provide long-lasting neuroprotection of CA1 hippocampus following transient global ischemia in rats. Exp Neurol 158:444-450.

Fillatreau S, Sweenie CH, McGeachy MJ, Gray D, Anderton SM (2002) B cells regulate autoimmunity by provision of IL-10. Nat Immunol 3:944-950.

Frenkel D, Huang Z, Maron R, Koldzic DN, Moskowitz MA, Weiner HL (2005) Neuroprotection by IL-10-producing MOG CD4+ T cells following ischemic stroke. J Neurol Sci 233:125-132.

Gee JM, Kalil A, Shea C, Becker KJ (2007) Lymphocytes: potential mediators of postischemic injury and neuroprotection. Stroke 38:783-788.

Gray D (1988) Population kinetics of rat peripheral B cells. J Exp Med 67:805816.

Grilli M, Barbieri I, Basudev H, Brusa R, Casati C, Lozza G, Ongini E (2000) Interleukin-10 modulates neuronal threshold of vulnerability to ischaemic damage. Eur J Neurosci 12:2265-2272.

Hurn PD, Subramanian S, Parker SM, Afentoulis ME, Kaler LJ, Vandenbark AA, Offner H (2007) T- and B-cell-deficient mice with experimental stroke have reduced lesion size and inflammation. J Cereb Blood Flow Metab 27:1798-1805

Kim JM, Rasmussen JP, Rudensky AY (2007) Regulatory T cells prevent catastrophic autoimmunity throughout the lifespan of mice. Nat Immunol 8:191-197.

Kleinschnitz C, Schwab N, Kraft P, Hagedorn I, Dreykluft A, Schwarz T, Austinat M, Nieswandt B, Wiendl H, Stoll G (2010) Early detrimental T-cell effects in experimental cerebral ischemia are neither related to adaptive immunity nor thrombus formation. Blood 115:3835-3842.

LeBien TW, Tedder TF (2008) B lymphocytes: how they develop and function. Blood 112:1570-1580.

Liesz A, Suri-Payer E, Veltkamp C, Doerr H, Sommer C, Rivest S, Giese T, Veltkamp R (2009) Regulatory T cells are key cerebroprotective immunomodulators in acute experimental stroke. Nat Med 15:192-199. 
Lund FE (2008) Cytokine-producing B lymphocytes: key regulators of immunity. Curr Opin Immunol 20:332-338.

Mann MK, Maresz K, Shriver LP, Tan Y, Dittel BN (2007) B cell regulation of CD4+CD25+T regulatory cells and IL-10 via B7 is essential for recovery from experimental autoimmune encephalomyelitis. J Immunol 178:3447-3456.

Matsushita T, Horikawa M, Iwata Y, Tedder TF (2010) Regulatory B cells (B10 cells) and regulatory T cells have independent roles in controlling experimental autoimmune encephalomyelitis initiation and late-phase immunopathogenesis. J Immunol 185:2240-2252.

Mellor AL, Baban B, Chandler PR, Manlapat A, Kahler DJ, Munn DH (2005) Cutting edge: $\mathrm{CpG}$ oligonucleotides induce splenic CD19+ dendritic cells to acquire potent indoleamine 2,3-dioxygenase-dependent $\mathrm{T}$ cell regulatory functions via IFN type 1 signaling. J Immunol 175:5601-5605.

Offner H, Subramanian S, Parker SM, Afentoulis ME, Vandenbark AA, Hurn PD (2006a) Experimental stroke induces massive, rapid activation of the peripheral immune system. J Cereb Blood Flow Metab 26:654-665.

Offner H, Subramanian S, Parker SM, Wang C, Afentoulis ME, Lewis A, Vandenbark AA, Hurn PD (2006b) Splenic atrophy in experimental stroke is accompanied by increased regulatory $\mathrm{T}$ cells and circulating macrophages. J Immunol 176:6523-6531.

Offner H, Vandenbark AA, Hurn PD (2009) Effect of experimental stroke on peripheral immunity: CNS ischemia induces profound immunosuppression. Neuroscience 158:1098-1111.

Ooboshi H, Ibayashi S, Shichita T, Kumai Y, Takada J, Ago T, Arakawa S, Sugimori H, Kamouchi M, Kitazono T, Iida M (2005) Postischemic gene transfer of intrleukin-10 protects against both focal and global brain ischemia. Circulation 111:913-919.

Planas AM, Gorina R, Chamorro A (2006) Signaling pathways mediating inflammatory responses in brain ischaemia. Biochem Soc Trans 34:1267-1270.

Ren X, Akiyoshi K, Vandenbark AA, Hurn PD, Offner H (2011) CD4+FoxP3 + regulatory T-cells in cerebral ischemic stroke. Metab Brain Dis 26:87-90.

Roth R, Mamula MJ (1997) Trafficking of adoptively transferred B lymphocytes in B-lymphocyte-deficient mice. J Exp Biol 200:2057-2062.

Spera PA, Ellison JA, Feuerstein GZ, Barone FC (1998) IL-10 reduces rat brain injury following focal stroke. Neurosci Lett 251:189-192.

Tian J, Zekzer D, Hanssen L, Lu Y, Olcott A, Kaufman DL (2001) Lipopolysaccharide-activated B cells down-regulate Th1 immunity and pevent autoimmune diabetes in nonobese diabetic mice. J Immunol 167:1081-1089.

Vila N, Castillo J, Dávalos A, Esteve A, Planas AM, Chamorro A (2003) Levels of anti-inflammatory cytokines and neurological worsening in acute ischemic stroke. Stroke 34:671-675.

Wang Q, Tang XN, Yenari MA (2007) The inflammatory response in stroke. J Neuroimmunol 184:53-68.

Yanaba K, Bouaziz JD, Haas KM, Poe JC, Fujimoto M, Tedder TF (2008) A regulatory $\mathrm{B}$ cell subset with a unique $\mathrm{CD} 1 \mathrm{~d}^{\text {hi }} \mathrm{CD} 5+$ phenotype controls $T$ cell-dependent inflammatory responses. Immunity 28:639-650.

Yilmaz G, Arumugam TV, Stokes KY, Granger DN (2006) Role of T lymphocytes and interferon-gamma in ischemic stroke. Circulation 113: 2105-2112. 